Research Article

\title{
Relationships between Hydropower Generation and Rainfall-Gauged and Ungauged Catchments from Sri Lanka
}

\author{
Anushka Perera and Upaka Rathnayake \\ Department of Civil Engineering, Faculty of Engineering, Sri Lanka Institute of Information Technology, Colombo, Sri Lanka \\ Correspondence should be addressed to Upaka Rathnayake; upakasanjeewa@gmail.com
}

Received 25 March 2020; Revised 27 May 2020; Accepted 7 July 2020; Published 27 July 2020

Academic Editor: Luis Cea

Copyright (C) 2020 Anushka Perera and Upaka Rathnayake. This is an open access article distributed under the Creative Commons Attribution License, which permits unrestricted use, distribution, and reproduction in any medium, provided the original work is properly cited.

\begin{abstract}
The relationship between the rainfall and minihydropower generation in a catchment is highly nonlinear. Therefore, the prediction of minihydropower generation is complex. However, the prediction is important in optimizing the control of electricity generation under various environmental conditions. Ongoing climate variabilities have completely changed the minihydropower generation to some parts of the world, and it is significant. Therefore, this paper presents results from two soft-computing studies in searching the relationships between rainfall and the generated hydropower. The first study was carried out for a gauged catchment; however, the second was carried for an ungauged catchment. Results revealed that there is an acceptable correlation in between the rainfall and hydropower generation for the gauged catchment and a marginal contribution to the ungauged catchment.
\end{abstract}

\section{Introduction}

Renewable energy is generated from natural resources including rainwater, wind, sun-light, and ocean tides. Usage of more renewable resources for power generation has taken the world's attention due to the depletion of fossil fuels and environmental concerns $[1,2]$. Despite the fact that a welldeveloped hydroelectric potential might not be capable of meeting the future demand for electricity, minihydropower has been the center of attraction due to its economic viability and environmental-friendly operation, mostly for developing countries [3-7]. Minihydropower has become common in most of the countries while being highly popular in Asia, Africa, and South America. Some of the potential resources for hydropower development are yet to be explored [6]. However, minihydropower is an easily operational, mature, and technologically reliable energy source with over 50-year life cycle. In addition, it is more efficient than the other sources such as wind and solar energy $[8,9]$. Therefore, minihydropower is utilized widely around the world for power generation. As an example, around $324 \mathrm{MW}$ are fed to the national grid in Thailand from their minihydropower stations [10]. However, they still have the potential to develop more hydropower from nonutilized resources. Similar cases can be found in many other countries including Sri Lanka.

However, predicting the available hydropower from already-developed minihydropower plants is a challenging task due to various reasons, including climate variabilities [11]. Nevertheless, the relationship of hydropower generation with rainfall is highly nonlinear [12]. Therefore, power predictions are challenging. Minihydropower prediction, if possible, is important for future planning processes. Proper planning in the energy sector could save millions of money.

Over the past years, use of soft-computing techniques has been popular among researchers to predict the power generation from hydropower systems in the world. Softcomputing techniques such as Artificial Neural Networks (ANNs), Data mining (DM), Support vector machines (SVM), Adaptive Neuro-Fuzzy Interference System (ANFIS), and Genetic Programming (GP) have widely been used in power generation prediction models [13-18]. Among these techniques, the ANN is considered to the most common soft-computing technique used. ANNs are inspired 
by biological neural networks and designed to create relationships among different variables [19-21]. Generally, ANNs do not depend on preassumptions for determining the nature of the relationship between the input and output variables, and the model is generated without a prior raw data transformation $[22,23]$. Therefore, ANNs are widely used for the prediction of future events, and their performance has been evaluated in the literature vastly $[24,25]$.

The literature presents different studies carried out to predict hydropower generation using ANNs. Cobaner [26] studied to predict that the hydropower energy potential using ANN has used a single hidden-layered feed-forward neural network trained using Levenberg-Marquadt algorithm. This model has been successful in the prediction of the monthly and annual average hydroelectric energy of an existing irrigation dam. Miao [27] studied on forecasting of small hydropower generation using an improved BP neural network. Particle swarm optimization algorithm was incorporated in this analysis. Results show that the method proposed in this paper is highly accurate based on the validation through the example.

Several studies have been carried out in Sri Lanka to investigate the impact of climate variability on the power generation in minihydropower plants. Perera [28] have studied on the impact of expected climate change on the hydropower generation using the Erathna run-of-the-river hydropower plant. Furthermore, Khaniya [29] studied on the impact of climate variability on hydropower generation using the Denawaka Ganga minihydropower plant. However, they were statistical models to observe the recent trends in minihydropower due to ongoing climate variabilities. In addition, Ratnayake [30] has predicted the hydropower potential of the ungauged river basin in Gin river, Sri Lanka. Apart from these, no comprehensive model has been built to predict the hydropower generation of minihydropower plants using soft-computing techniques.

Therefore, as a country which is highly relying on hydropower, predicting the potential hydropower generation in the future years is extremely important to balance the energy demand and the country's economic model. To the authors' knowledge, there is no such prediction model in the literature for Sri Lanka. Therefore, such a study would pave the passage to perform proper planning in energy demand in future Sri Lanka. Therefore, highly polluted nonrenewable energy usage in the country's coal power and fossil fuel power can be managed well for a sustainable Sri Lanka. This would surely contribute highly to the economy of the developing Sri Lanka.

Hence, this study, as the first study in Sri Lanka, has focused on using soft-computing techniques to identify the relationships between hydropower and rainfall using historical rainfall data and power generation to address this existing research gap. Interestingly, two minihydropower plants, one with a gauged catchment and the other with an ungauged catchment, were selected for the analysis. The relationships between rainfall and the hydropower generation were derived to both cases, gauged catchment and ungauged catchment. Acceptable and interesting results were obtained and presented here.

\section{Denawaka Ganga and Erathna Minihydropower Plants}

Denawaka Ganga and Erathna minihydropower plants are in Ratnapura district of Sri Lanka. Ratnapura district belongs to the wet zone of the country, and it has many minihydropower plants due to its water resources and mountainous geography. Denawaka Ganga and Erathna minihydropower stations are owned by the private sector and started their operation in Feb-2012 and Jan-2011, respectively. The Denawaka Ganga minihydropower plant receives water from a $172.58 \mathrm{~km}^{2}$ catchment area, as shown in Figure 1. The power plant has a capacity of 7.2 MW hydroelectric generation. However, the Erathna catchment (shown in Figure 1) is significantly smaller compared to the Denawaka Ganga catchment and has only $14.5 \mathrm{~km}^{2}$. Nevertheless, it has a capacity of $10 \mathrm{MW}$ hydropower. There are no rain gauges inside the Erathna catchment as it is a conserved area. In contrast, the Denawaka Ganga catchment has several rain gauges.

\section{Neural Network Models for Catchments}

As it was stated above, the Denawaka catchment is a gauged catchment. It has five rain gauges (refer Figure 1). The historical rainfall data for these five gauges were obtained from the Meteorology Department of Sri Lanka. Monthly generated hydropower for the Denawaka Ganga minihydropower (since it's starting, February-2012) was collected from the Denawaka Ganga minihydropower plant. Then, the neural network models were trained to relate the following nonlinear function (equation (1)).

$$
\text { Power }_{\text {Denawaka }}=\phi_{1}\left(R F_{i}, R F_{i+1}, \ldots R F_{n}\right) \text {. }
$$

Similar to the abovementioned modeling techniques, the Erathna minihydropower plant was modeled using neural networks. However, as Perera and Rathnayake [28] suggested, two sets of rain gauges were selected to observe the relationship between rainfall and the power generation. Set 1 includes Galaboda Estate, Keragala, Pussella S.P., Maliboda, and Anhetigama Estate rain gauges, whereas the set 2 includes Laxapana, Maskeliya, Maussakele, and Hapugastenna Estate rain gauges (please refer Figure 1). As it was already stated, the Erathna catchment is an ungauged catchment in Sri Lanka. Set 1 and set 2 rain gauges are to the west and to the east of the Erathna catchment, respectively. In addition, the Samanala mountain range, which is highly elevated than both the Erathna catchment and set 2 rain gauges, is positioned in between them. Therefore, the relationships were modeled accordingly and given in equations (2) and (3). Monthly generated hydropower for the Erathna minihydropower (since it's starting, January 2011) was collected from Erathna minihydropower plant.

$$
\begin{aligned}
& \text { Power }_{\text {Erathna }}=\phi_{2}\left(R F_{i}, R F_{i+1}, \ldots R F_{n}\right)_{\text {set1 } 1}, \\
& \text { Power }_{\text {Erathna }}=\phi_{3}\left(R F_{i}, R F_{i+1}, \ldots R F_{n}\right)_{\text {set2 } 2} .
\end{aligned}
$$

ANNs model were developed using MATLAB computing environment (version 8.5.0.197613-R2015a) with the 


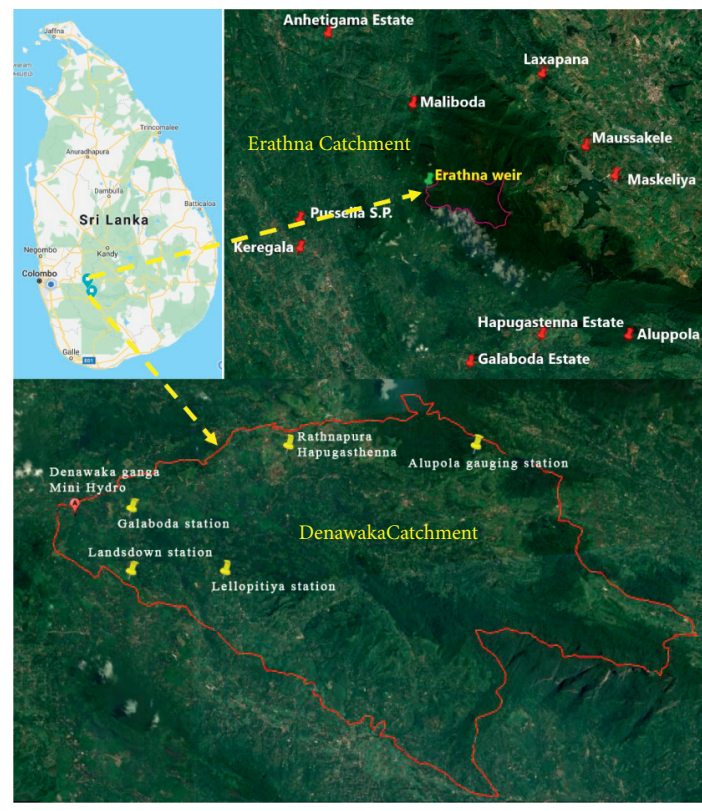

Figure 1: Denawaka Ganga and Erathna catchments.

abovementioned training algorithms. A nonlinear Autoregressive network with exogenous inputs (NARX) was used as the input model to predict hydropower generation $[y(t)]$ with past values of $x(t)$ and $y(t)$, where different $x(t)$ parameters (rainfall values) for series of time steps determines $y(t)$, during ANN training. The ANN was trained with $60 \%$ of randomly selected time steps. In addition, $20 \%$ each of target time steps were used for testing and validation. Performance of the developed model was determined using MSE and correlation coefficient $(R)$.

Levenberg-Marquadt (LM), Bayesian Regularization (BR), and Scaled Conjugate Gradient (SCG) algorithms were used to train the neural network. However, LM is most commonly used in climate prediction as the optimization algorithm. The algorithm is designed to approach secondorder training speed without computing the Hessian matrix. Nevertheless, Bayesian regularization and Scaled Conjugate Gradient algorithms are widely used in the ANN architecture [31, 32]. Detailed descriptions of these algorithms LM, BR, and SCG can be found in the work of Perera and Rathnayake [28].

\section{Results and Discussion}

4.1. Results for the Denawaka Minihydropower Plant. Table 1 exhibits the coefficient of correlation for the predicted and actually generated hydropower by the ANN for Denawaka Ganga minihydropower station power generation. Results are given here against three algorithms for three trials. Correlation coefficients are presented for the three processes (training, validation, and test) and overall. Results exhibited that LM algorithm ( $2^{\text {nd }}$ trial) outperforms the other algorithms.

Figure 2 presents the selected results $\left(2^{\text {nd }}\right.$ trial of $L M$ algorithm) from Table 1 . The training process shows a wellaccepted correlation coefficient $(R=0.9)$. The overall
TABle 1: Coefficient of correlation for Denawaka Ganga minihydropower plant power generation.

\begin{tabular}{lccccc}
\hline \multirow{2}{*}{ Algorithm } & \multirow{2}{*}{ Trials } & \multicolumn{4}{c}{ Coefficient of correlation } \\
& & Training & Validation & Test & All \\
\hline \multirow{3}{*}{ LM } & 1 & 0.84 & 0.36 & 0.79 & 0.71 \\
& 2 & 0.91 & 0.68 & 0.57 & 0.78 \\
& 3 & 0.01 & 0.21 & 0.63 & -0.11 \\
\hline \multirow{3}{*}{ BR } & 1 & 0.78 & 0.71 & 0.75 & -0.11 \\
& 2 & 0.76 & 0.10 & 0.73 & -0.11 \\
& 3 & 0.77 & 0.73 & 0.74 & -0.11 \\
\hline \multirow{3}{*}{ SCG } & 1 & 0.72 & 0.64 & 0.66 & 0.69 \\
& 2 & 0.46 & 0.59 & 0.79 & 0.51 \\
& 3 & 0.84 & 0.11 & 0.64 & 0.68 \\
\hline
\end{tabular}

coefficient lies around 0.7 , and this is an acceptable correlation for nonlinear processes, where it is related to changing climatic conditions. Nevertheless, the validation correlation coefficient is around 0.68 , which is slightly to the lower side even though it is positively correlated.

Table 2 showcases the performance of the developed ANN model for Denawaka Ganga minihydropower generation. The $2^{\text {nd }}$ trial for LM shows a mean squared error of 1.19 at the 11 th epoch. This is an acceptable performance to the prediction of hydropower generation. Furthermore, the variations of MSE with the epoch for the three trials for LM algorithm are shown in Figure 3. They clearly show the computational rapidness of the results.

4.2. Results for the Erathna Minihydropower Plant. As it was stated earlier that Erathna is an ungauged small catchment, however, it produces $10 \mathrm{MW}$ of electricity. The results are presented here for two sections (power generation with rainfall of 1 set of rain gauges and power generation with rainfall of 2 sest of rain gauges). Table 3 presents the correlation coefficient for the actual hydropower generation and predicted hydropower generation from the rainfalls from set 1. Algorithms LM and BR show a better performance compared to SCG algorithm. However, the corresponding MSE are significantly higher for these two cases (refer Table 4 ). They are around $1.03 \times 10^{6}$ and $4.8 \times 10^{5}$, respectively. The ideal MSE for such an analysis is zero; however, lowered MSE values are acceptable. However, the obtained MSE values for Erathna minihydro are in millions. Therefore, Erathna power generation does not have a good correlation to the set 1 rainfall data.

As it was stated in the preceding paragraph, the MSE values for other algorithms and at different trails are given in Table 4. It is clearly seen that the MSE values are significantly higher. In addition, ANN programs consume significant time durations (number of epochs). Therefore, the unsuitability of the ANN to predict Erathna hydropower generation based on the rainfall to set 1 rain gauges is established.

Similar observations can be seen in Erathna power plant hydropower prediction compared to rainfall of set 2 rain gauges. Table 5 shows the correlation coefficient for the predicted and recorded hydropower generation for set 2 rain gauges. LM algorithm has shown the best correlation; 


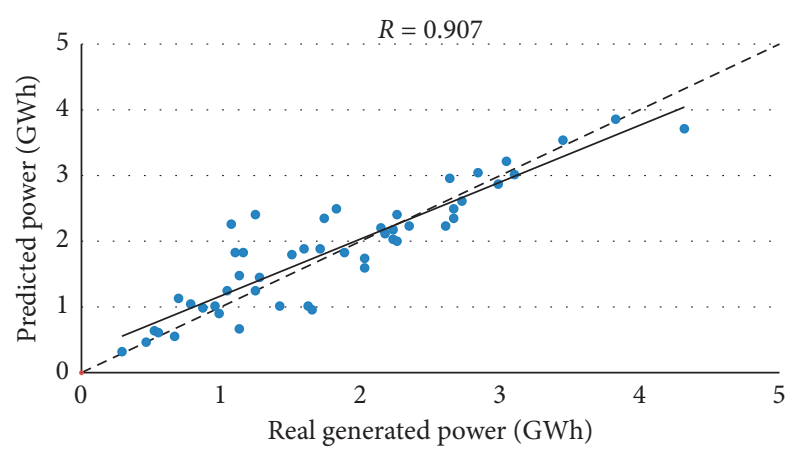

(a)

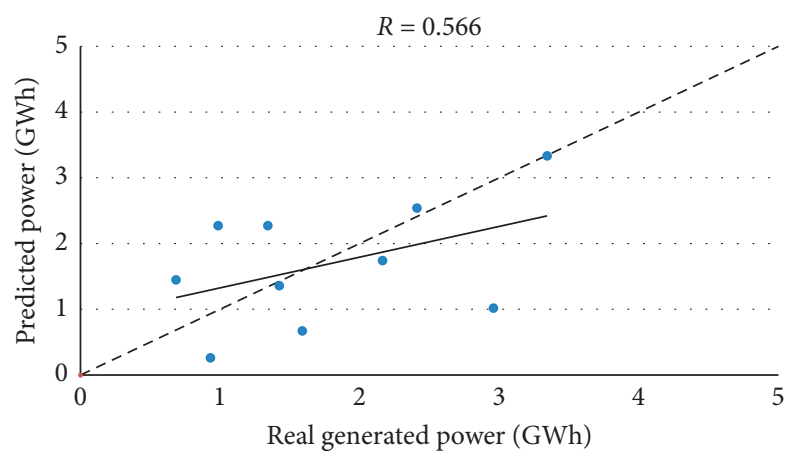

(c)

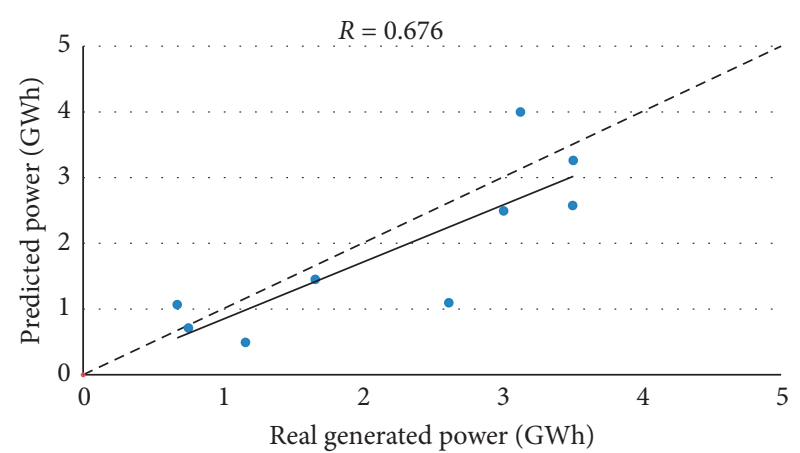

(b)

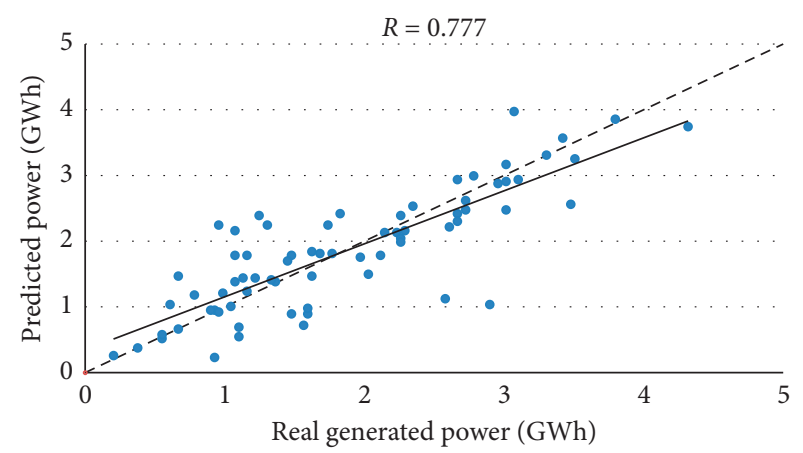

(d)

Figure 2: ANN results for LM algorithm for Denawaka Ganga minihydropower generation. (a) For training. (b) For validation. (c) For test. (d) For all.

TABLe 2: Performance of the developed ANN model- Denawaka Ganga minihydropower station.

\begin{tabular}{lcccccc}
\hline \multirow{2}{*}{ Algorithm } & \multicolumn{2}{c}{ Validation performance } \\
& \multicolumn{2}{c}{ Trial 1 } & \multicolumn{2}{c}{ Trial 2 } & Trial 3 \\
& MSE & Number of epochs & MSE & Number of epochs & MSE & Number of epochs \\
\hline LM & 1.08 & 3 & 1.19 & 11 & 1.28 & 0.36 \\
BR & 0.32 & 124 & 0.42 & 376 & 1.14 & 83 \\
SCG & 0.32 & 5 & 0.51 & 3 & 8 \\
\hline
\end{tabular}

however, epochs in Table 6 have exhibited the unsuitability of the ANN for prediction of hydropower in the Erathna minihydropower plant. This conclusion was justified by Table 6.

The results of the abovementioned studies can be used at various planning stages. As it was stated in the introduction, the results are beneficial for the energy demand in the country at future climate scenarios. Planners can preidentify when to what extent they have to operate the minihydropower plants while protecting the environment. When it comes to energy demands, the planner usually neglects the surrounding environment. This is usually due to the economic factors (at least, in the developing world). However, if performed correctly, the future plans can be drafted as per the climate models and, then, to keep a good environmental flow in the hydropower stations. It is a very usual fact that many environmentalists raise their voice against the minihydropower plants because of the low or no environmental flow in the downstream channel from the head raise weir.
This is questionable in most of the minihydropower plants in Sri Lanka, and the ecological damage at downstream of the minihydropower plants are witnessed by the authors of this research paper. Even though it is not a minihydropower plant, the Upper Kothmale hydropower plant is such an example. The world famous St. Clair falls is no longer the previously seen St. Clair waterfall due to the hydropower development [33-36]. This is very important in hydropower development, and ecological aspects should be well planned. This is to minimize the ecological damage by the hydropower stations [37-41]. Therefore, the results of this research can be very useful in the protection of the ecology downstream of the minihydropower plant.

The prediction model can be handy in feeding the climate data from various models. Regional climate models such as ACCESS1 [42], CNRM-CM5-CSIRO-CCAM [43], MPI-ESM-LR [44], and REMO2009 [45, 46] can be used to obtain the future rainfall to the catchment. These rainfall values have to be corrected for the biases. Many researchers accept the linear bias correction. Corrected rainfalls can be 


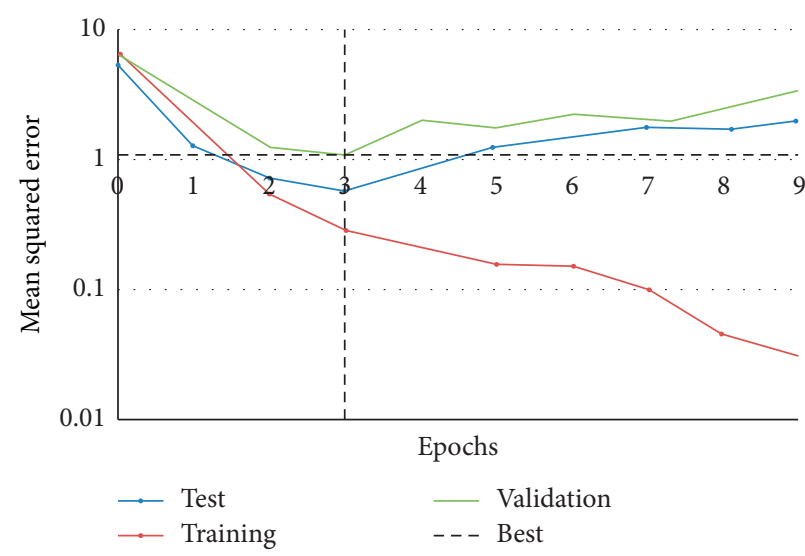

(a)

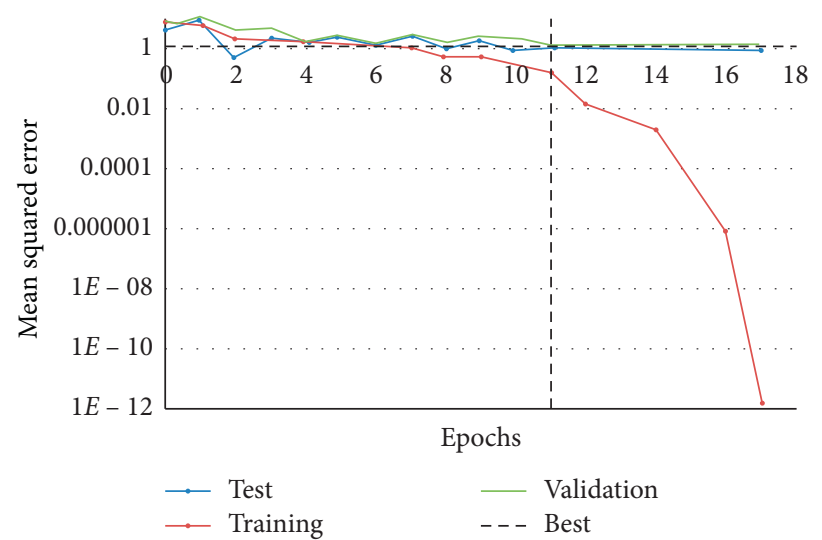

(b)

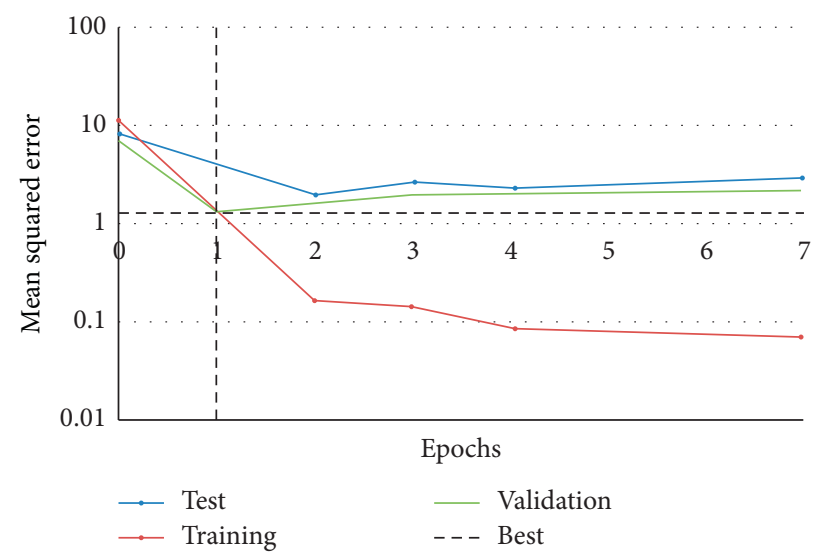

(c)

FIgURE 3: Performance of LM algorithm in achieving results. (a) For trial 1. (b) For trial 2. (c) For trial 3.

TABle 3: Coefficient of correlation for Erathna minihydropower plant power generation for set 1 rain gauges.

\begin{tabular}{|c|c|c|c|c|c|}
\hline \multirow{2}{*}{ Algorithm } & \multirow{2}{*}{ Trials } & \multicolumn{4}{|c|}{ Coefficient of correlation } \\
\hline & & Training & Validation & Test & All \\
\hline \multirow{3}{*}{ LM } & 1 & 0.39 & 0.78 & 0.23 & 0.42 \\
\hline & 2 & 0.90 & 0.85 & 0.69 & 0.86 \\
\hline & 3 & 0.74 & 0.68 & 0.72 & 0.73 \\
\hline \multirow{3}{*}{$\mathrm{BR}$} & 1 & 0.99 & 0.68 & 0.95 & 0.73 \\
\hline & 2 & 0.92 & 0.81 & 0.9 & 0.73 \\
\hline & 3 & 0.99 & 0.66 & 0.95 & 0.73 \\
\hline \multirow{3}{*}{ SCG } & 1 & 0.77 & 0.90 & 0.39 & 0.76 \\
\hline & 2 & 0.77 & 0.73 & 0.75 & 0.76 \\
\hline & 3 & 0.71 & 0.85 & 0.66 & 0.73 \\
\hline
\end{tabular}

TABLE 4: Performance of the developed ANN model- Erathna minihydropower station for set 1 speed rain gauges.

\begin{tabular}{lcccccc}
\hline & & & \multicolumn{2}{c}{ Validation performance } \\
Algorithm & & \multicolumn{2}{c}{ Trial 1 } & Trial 2 & Trial 3 \\
& MSE & Number of epochs & MSE & Number of epochs & MSE & Number of epochs \\
\hline LM & $2.42 \times 10^{6}$ & 0 & $1.03 \times 10^{6}$ & 4 & $2.48 \times 10^{6}$ & 3 \\
BR & $1.43 \times 10^{4}$ & 208 & $4.8 \times 10^{5}$ & 178 & $8.9 \times 10^{3}$ & 393 \\
SCG & $7.42 \times 10^{5}$ & 5 & $1.84 \times 10^{6}$ & 17 & $1.19 \times 10^{6}$ & 8 \\
\hline
\end{tabular}


TABLE 5: Coefficient of correlation for Erathna minihydropower plant power generation for set 2 rain gauges.

\begin{tabular}{|c|c|c|c|c|c|}
\hline \multirow{2}{*}{ Algorithm } & \multirow{2}{*}{ Trials } & \multicolumn{4}{|c|}{ Coefficient of correlation } \\
\hline & & Training & Validation & Test & All \\
\hline \multirow{3}{*}{ LM } & 1 & 0.82 & 0.36 & 0.55 & 0.72 \\
\hline & 2 & 0.76 & 0.79 & 0.78 & 0.77 \\
\hline & 3 & 0.96 & 0.90 & 0.60 & 0.88 \\
\hline \multirow{3}{*}{$\mathrm{BR}$} & 1 & 0.99 & 0.67 & 0.93 & 0.88 \\
\hline & 2 & 0.96 & 0.52 & 0.87 & 0.88 \\
\hline & 3 & 0.96 & 0.61 & 0.91 & 0.88 \\
\hline \multirow{3}{*}{ SCG } & 1 & 0.71 & 0.79 & 0.72 & 0.72 \\
\hline & 2 & 0.66 & 0.74 & 0.77 & 0.69 \\
\hline & 3 & 0.85 & 0.63 & 0.75 & 0.80 \\
\hline
\end{tabular}

TABle 6: Performance of the developed ANN model- Erathna minihydropower station for set 2 rain gauges.

\begin{tabular}{lcccccc}
\hline & & & \multicolumn{2}{c}{ Validation performance } \\
Algorithm & \multicolumn{2}{c}{ Trial 1 } & \multicolumn{2}{c}{ Trial 2 } & Trial 3 \\
& MSE & Number of epochs & MSE & Number of epochs & MSE & Number of epochs \\
\hline LM & $2.51 \times 10^{6}$ & 2 & $1.50 \times 10^{6}$ & 2 & $6.72 \times 10^{5}$ & 11 \\
BR & $1.36 \times 10^{4}$ & 324 & $2.72 \times 10^{5}$ & 172 & $2.51 \times 10^{5}$ & 206 \\
SCG & $9.47 \times 10^{5}$ & 8 & $1.29 \times 10^{6}$ & 3 & $2.19 \times 10^{6}$ & 23 \\
\hline
\end{tabular}

easily fed to the saved ANN model to reassess the hydropower development predictions. This whole process can be automatically carried out as an online arrangement. In addition, the model can be further developed using the real present rainfall, however, without the physical appearance but online feeding systems.

\section{Conclusions}

Artificial neural network results reveal the relationships between rainfall and the hydropower generation of two minihydropower plants in Sri Lanka. Gauged catchment (Denawaka Ganga) shows a significant correlation (the correlation coefficient is greater than or equal to 0.57 at 1.19 of MSE and 11 epochs) between the catchment rainfall and the hydropower generation. Therefore, the prediction model generates acceptable results at low computational cost and lowest mean squared errors. Therefore, the accuracy, reliability, and the robustness of the prediction model can be accepted.

However, an ungauged catchment (Erathna catchment) does not show a good correlation between the rainfall and the hydropower generation. Even though the correlation coefficients are greater than 0.6 (compared to Denawaka Ganga), the MSEs are significantly higher for Erathna hydropower for both rain gauge sets. MSEs are around $10^{5}$ or $10^{6}$ orders. Therefore, the results are not reliable. In addition, the Erathna minihydropower plant has a small catchment area, which is inside a conserved area, and thus, it is unable to place any real rain gauges. However, the surrounding rain gauges to the Erathna catchment do not support the hydropower generation of the catchment. Therefore, it can be concluded, herein, that the gauged catchment's rainfall supports the prediction of hydropower production. Perera and Rathnayake [28] have suggested to cluster the rain gauges around the Erathna catchment into two major groups, one covering to the Sri Pada mountain range and the other is the western side of the catchment. The analyses were carried out to a similar approach here; however, there is no significant correlation between the rainfall to the hydropower generation in the Erathna catchment.

The limitations of rainfall data inside the Erathna catchment have produced insignificant results. Therefore, this can be reanalyzed had there been at least single rain gauge placed inside the catchment. However, it is impossible, as Erathna is a conserved area.

Nevertheless, the conclusions made here can be highly useful for the energy planners in the country. The climate models can produce future climate data under different scenarios of the Representative Concentration Pathway (RCPs-RCP2.6, RCP4.5, RCP6, and RCP8.5). These future climate data can be used to recall the developed prediction ANN model to obtain the future hydropower developments. Therefore, the Denawaka hydropower plant can be used for future predictions using various climatic scenarios. However, the Erathna hydropower plant would not be used for such a case due to its lowered-quality results.

\section{Data Availability}

The historical rainfall and hydropower data and the analysis data are available from the corresponding author upon request.

\section{Conflicts of Interest}

The authors declare that there are no conflicts of interest.

\section{Acknowledgments}

The authors would like to convey their sincere gratitude to their home university, Sri Lanka Institute of Information 
Technology, Sri Lanka, for providing finance to carry out the research work. In addition, they would like to thank Country Energy (Pvt) Ltd., Sri Lanka, for their support in providing required hydropower information for this research work. This research was conducted in the Faculty of Engineering, Sri Lanka Institute of Information Technology, Sri Lanka, with the financial help from the institute for data purchasing.

\section{References}

[1] S. P. Adhau, R. M. Moharil, and P. G. Adhau, "Mini-hydro power generation on existing irrigation projects: case study of Indian sites," Renewable and Sustainable Energy Reviews, vol. 16, no. 7, pp. 4785-4795, 2012.

[2] J. A. Laghari, H. Mokhlis, A. H. A. Bakar, and H. Mohammad, "A comprehensive overview of new designs in the hydraulic, electrical equipments and controllers of mini hydro power plants making it cost effective technology," Renewable and Sustainable Energy Reviews, vol. 20, pp. 279-293, 2013.

[3] K. V. Alexander, E. P. Giddens, and A. M. Fuller, "Axial-flow turbines for low head microhydro systems," Renewable Energy, vol. 34, no. 1, pp. 35-47, 2009.

[4] K. V. Alexander and E. P. Giddens, "Microhydro: cost-effective, modular systems for low heads," Renewable Energy, vol. 33, no. 6, pp. 1379-1391, 2008.

[5] K. V. Alexander, E. P. Giddens, and A. M. Fuller, "Radial-and mixed-flow turbines for low head microhydro systems," Renewable Energy, vol. 34, no. 7, pp. 1885-1894, 2009.

[6] O. Paish, "Small hydro power: technology and current status," Renewable and Sustainable Energy Reviews, vol. 6, no. 6, pp. 537-556, 2002.

[7] A. Bartle, "Hydropower potential and development activities," Energy Policy, vol. 30, no. 14, pp. 1231-1239, 2002.

[8] F. H. Schwartz and M. Shahidehpour, "Small hydro as green power mohammad shahidehpour energy in society: how we make it renewable versus fossil generation," in Proceedings of the IEEE EIC Climate Change Technology, Ottawa, ON, Canada, May 2006.

[9] K. Kusakana, J. L. Munda, and A. A. Jimoh, "Economic and environmental analysis of micro hydropower system for rural power supply," in Proceedings of the 2nd IEEE International Conference on Power and Energy (PECon 08), pp. 441-444, Johor Bahru, Malaysia, December 2008.

[10] N. Kittner, S. H. Gheewala, and D. M. Kammen, "Energy return on investment (EROI) of mini-hydro and solar PV systems designed for a mini-grid," Renewable Energy, vol. 99, pp. 410-419, 2016.

[11] M. M. Hasan and G. Wyseure, "Impact of climate change on hydropower generation in Rio Jubones Basin, Ecuador," Water Science and Engineering, vol. 11, no. 2, pp. 157-166, 2018.

[12] A. T. Hammid, M. H. B. Sulaiman, and A. N. Abdalla, "Prediction of small hydropower plant power production in Himreen Lake dam (HLD) using artificial neural network," Alexandria Engineering Journal, vol. 57, no. 1, pp. 211-221, 2018.

[13] Z. Liu, W. Gao, N. Carolina, and E. Muljadi, "Wind power plant prediction by using neural networks preprint," in Proceedings of the 2012 IEEE Energy Conversion Conference and Exposition, Raleigh, NC, USA, September 2012.

[14] P. Coulibaly, F. Anctil, and B. Bobee, "Neural network-based long-term hydropower forecasting system," Computer-Aided
Civil and Infrastructure Engineering, vol. 15, no. 5, pp. 355364, 2000.

[15] F. Othman and M. Naseri, "Reservoir inflow forecasting using artificial neural network," International Journal of Physical Sciences, vol. 6, no. 3, pp. 434-440, 2011.

[16] M. Cobaner, T. Haktanir, and O. Kisi, "Prediction of hydropower energy using ANN for the feasibility of hydropower plant installation to an existing irrigation dam," Water Resources Management, vol. 22, no. 6, pp. 757-774, 2008.

[17] C. T. Cheng, J. Y. Lin, Y.-G Sun, and K. Chau, "Long-term prediction of discharges in manwan hydropower using adaptive-network-based fuzzy inference systems models," in Lecture Notes in Computer Science, vol. 3612, pp. 1152-1161, Springer-Verlag, Berlin, Heidelberg, 2005.

[18] H. R. Maier and G. C. Dandy, "Neural networks for the prediction and forecasting of water resources variables: a review of modelling issues and applications," Environmental Modelling \& Software, vol. 15, no. 1, pp. 101-124, 2000.

[19] E. Betiku, S. S. Okunsolawo, S. O. Ajala, and O. S. Odedele, "Performance evaluation of artificial neural network coupled with generic algorithm and response surface methodology in modeling and optimization of biodiesel production process parameters from shea tree (Vitellaria paradoxa) nut butter," Renewable Energy, vol. 76, pp. 408-417, 2015.

[20] H. Ebrahimi and T. Rajaee, "Simulation of groundwater level variations using wavelet combined with neural network linear regression and support vector machine," Global and Planetary Change, vol. 148, pp. 181-191, 2017.

[21] M. Ravansalar, T. Rajaee, and O. Kisi, "Wavelet-linear genetic programming: a new approach for modeling monthly streamflow," Journal of Hydrology, vol. 549, pp. 461-475, 2017.

[22] S. Agatonovic-Kustrin and R. Beresford, "Basic concepts of artificial neural network (ANN) modeling and its application in pharmaceutical research," Journal of Pharmaceutical and Biomedical Analysis, vol. 22, no. 5, pp. 717-727, 2000.

[23] S. Ibrić, M. Jovanović, Z Djurić et al., "Artificial neural networks in the modeling and optimization of aspirin extended release tablets with Eudragit L 100 as matrix substance," AAPS PharmSciTech, vol. 4, no. 1, pp. 62-70, 2003.

[24] P. C. Nayak, K. P. Sudheer, D. M. Rangan, and K. S. Ramasastri, "A neuro-fuzzy computing technique for modeling hydrological time series," Journal of Hydrology, vol. 291, no. 1-2, pp. 52-66, 2004.

[25] X. Wang, F. Liu, Y. Gao, C.-H. Xue, R. W. Li, and Q.-J. Tang, "Transcriptome analysis revealed anti-obesity effects of the Sodium Alginate in high-fat diet -induced obese mice," International Journal of Biological Macromolecules, vol. 115, pp. 861-870, 2018.

[26] M. Cobaner, T. Haktanir, and O. Kisi, "Prediction of hydropower energy using ANN for the feasibility of hydropower plant installation to an existing irrigation dam," Water Resource Management, vol. 22, pp. 757-774, 2008.

[27] L. I. Miao, H. D. Chang, T. Jin, Y. Wei, and L. Zheng, "Research on small hydropower generation forecasting method based on improved BP neural network," in Proceedings of the 2016 3rd International Conference on Materials Engineering, Manufacturing Technology and Control (ICMEMTC 2016), pp. 1085-1090, Taiyun, China, April 2016.

[28] A. Perera and U. Rathnayake, "Impact of climate variability on hydropower generation in an un-gauged catchment: Erathna run-of-the-river hydropower plant, Sri Lanka," Applied Water Science, vol. 9, no. 3, p. 57, 2019.

[29] B. Khaniya, H. G. Priyantha, N. Baduge, H. Azamathulla, and U. Rathnayake, "Impact of climate variability on hydropower 
generation: a case study from Sri Lanka," ISH Journal of Hydraulic Engineering, vol. 26, no. 3, pp. 301-309, 2020.

[30] A. S. Ratnayake and A. Pitawala, "Prediction of ungauged river basin for hydropower potential and flood risk mitigation: a case study at Gin river, Sri Lanka," Interdisciplinary Environmental Review, vol. 15, no. 4, p. 203, 2014.

[31] F. Burden and D. Winkler, "Bayesian regularization of neural networks," Methods in Molecular Biology (Clifton, N.J.), vol. 458, pp. 25-44, 2008.

[32] D. J. C. MacKay, "A practical Bayesian framework for backpropagation networks," Neural Computation, vol. 4, no. 3, pp. 448-472, 1992.

[33] P. Meier and M. Munasinghe, "Greenhouse gas emission reduction: a case study of Sri Lanka," The Energy Journal, vol. 16, no. 4, 1995.

[34] H. K. Nandalal, "Importance of public participation in project implementation: upper Kotmale hydropower project in Sri Lanka," in Proceedings of the International Conference on Small Hydropower-Hydro Sri Lanka, vol. 1-7, Kandy, Sri Lanka, January 2007.

[35] M. Ranasinghe, "Bounds on the value of waterfalls: a case study from a hydropower project," Project Appraisal, vol. 12, no. 3, pp. 185-192, 1997.

[36] R. A. L. Ranawake, Hydropower Industry-Sri Lanka; Waterfalls-Sri Lanka, Department of Mechanical Engineering, University of Moratuwa, Moratuwa, Sri Lanka, 2011.

[37] A. Briones-Hidrovo, J. Uche, and A. Martínez-Gracia, "Determining the net environmental performance of hydropower: a new methodological approach by combining life cycle and ecosystem services assessment," Science of the Total Environment, vol. 712, Article ID 136369, 2020.

[38] Z.-K. Feng, S. Liu, W.-J. Niu, S.-S. Li, H.-J. Wu, and J.-Y. Wang, "Ecological operation of cascade hydropower reservoirs by elite-guide gravitational search algorithm with Lévy flight local search and mutation," Journal of Hydrology, vol. 581, Article ID 124425, 2020.

[39] A. R. Ghumman, H. Haider, I. Yousuf, and M. Shafiquzamman, "Sustainable development of small-sized hydropower plants: multilevel decision-making from site selection to optimal design," Arabian Journal for Science and Engineering, vol. 45, no. 5, pp. 4141-4159, 2020.

[40] R. Ramírez-Pisco, I. P. Djukic, C. L. Vásquez, A. Viloria, and N. Varela, "Feasibility study for a mini-hydropower plant in Dreznica, Bosnia, and Herzegovina," in Lecture Notes in Electrical Engineering, vol. 637, pp. 241-251, Springer, Singapore, 2020.

[41] T. Surasinghe, R. Kariyawasam, H. Sudasinghe, and S. Karunarathna, "Challenges in biodiversity conservation in a highly modified tropical river basin in Sri Lanka," Water, vol. 12 , no. 1, p. 26, 2019.

[42] G. Z. Ndhlovu and Y. E. Woyessa, "Modelling impact of climate change on catchment water balance, Kabompo river in Zambezi River basin," Journal of Hydrology: Regional Studies, vol. 27, Article ID 100650, 2020.

[43] S. Lamichhane and N. Shakya, "Integrated assessment of climate change and land use change impacts on hydrology in the Kathmandu Valley watershed, Central Nepal," Water, vol. 11, no. 10, p. 2059, 2019.

[44] R. Zhong, T. Zhao, Y. He, and X. Chen, "Hydropower change of the water tower of Asia in $21^{\text {st }}$ century: a case of the Lancang river hydropower base, upper Mekong," Energy, vol. 179, pp. 685-696, 2019.
[45] B. Bartók, I. Tobin, R. Vautard et al., "A climate projection dataset tailored for the European energy sector," Climate Services, vol. 16, Article ID 100138, 2019.

[46] V. P. Pandey, S. Dhaubanjar, L. Bharati, and B. R. Thapa, "Hydrological response of Chamelia watershed in Mahakali basin to climate change," Science of the Total Environment, vol. 650, pp. 365-383, 2019. 